\title{
The prognostic role of Gas6/Axl axis in solid malignancies: a meta-analysis and literature review
}

This article was published in the following Dove Press journal:

OncoTargets and Therapy

\author{
Sheng Zhang' \\ Xiang Shang $X u^{\prime}$ \\ Jie Xi Yang' \\ Jian Hui Guo' \\ Teng Fei Chao ${ }^{2}$ \\ YiXin Tong' \\ 'Department of Gastrointestinal \\ Surgery, Tongji Hospital, Tongji Medical \\ College, Huazhong University of \\ Science and Technology, Wuhan, China; \\ ${ }^{2}$ Department of Oncology, Tongji \\ Hospital, Tongji Medical College, \\ Huazhong University of Science \\ and Technology, Wuhan, China
}

Correspondence: YiXin Tong Department of Gastrointestinal Surgery, Tongji Hospital, Tongji Medical College, Huazhong University of Science and Technology, 1095 Jie Fang Avenue, Wuhan, Hubei, 430072, China

Tel +862783665216

Email yx_tong@I26.com
Background: Axl is a receptor tyrosine kinase that is involved in many pathological conditions and carcinogenesis. Gas6 is the major ligand of Axl. Activation of Gas6/Axl pathway is essential for cancer development. However, its prognostic significance in solid tumors remains unclear. Therefore, we performed this meta-analysis to elucidate the prognostic impact of Axl.

Methods: Published studies on Axl or Gas6 expression and overall survival (OS) and/or disease-free survival (DFS) were searched from databases. The outcome measurement is hazard ratio (HR) for OS or DFS related to Axl/Gas6 expression. Meta-analysis was performed using RevMan. The pooled HR was calculated by fixed-/random-effect models.

Results: A total of 3,344 patients from 25 studies were included. The results of meta-analysis showed that Axl overexpression was correlated with shorter OS (HR: 2.03, $p<0.0001$ ) and DFS (HR: $1.85, p<0.0001$ ). In subgroup analysis, Axl expression was significantly correlated with poor prognosis in hepatocellular, esophageal and lung cancer. Axl expression was associated with differentiation grade, TNM stage, lymph node and distant metastasis.

Conclusion: These results suggest that Axl overexpression is correlated with poor prognosis in solid tumors. This correlation varies among different types of cancers. More studies are needed to further investigate the prognostic value of Axl.

Keywords: Gas6/Axl, prognosis, solid tumor, biomarker, meta-analysis, overall survival, disease-free survival

\section{Introduction}

As a life-threatening disease, cancer is a major contributor to health care burden and increased human mortality. ${ }^{1}$ Multiple sequential genetic and epigenetic changes are involved in the process of carcinogenesis. The activation of Gas6/Axl signaling pathway has been found to play an important role during the process of cancer development and progression. The receptor tyrosine kinase Axl belongs to TAM (Tyro3, Axl and Mertk) family and is characterized by an extracellular domain consisting of 2 immunoglobulin-like domains in juxtaposition to 2 fibronectin type III domains, typical for cell adhesion molecules of the immunoglobulin superfamily. ${ }^{2-4}$ Axl plays a pivotal part in various physiological and pathological processes. When bound to its ligand Gas6, the activated Axl will induce the multiple downstream pathways and lead to resistance of apoptosis, and increased migration and growth. ${ }^{5}$

Upregulation of Gas6/Axl pathway has been found highly related to carcinogenesis. ${ }^{5}$ The overexpression of Axl has been underlined in several conditions especially in carcinogenesis. It has been found that Axl is overexpressed in various cancers such as breast cancer, lung cancer and gastrointestinal malignancies. Overexpression of Axl is reported to correlate with poor prognosis. ${ }^{5}$ These evidences suggest that Axl could be considered as a potential biomarker for evaluating prognosis in cancer patients. 
Although many anti-Axl inhibitors have been developed and launched into Phase I and II clinical trials and have showed some promising results, the comprehensive prognostic value of Gas6/Axl in solid tumors is still not clear. ${ }^{6}$ Therefore, we performed this meta-analysis and sought to evaluate the association between Axl expression and prognostic factors including overall survival (OS) and disease-free survival (DFS) in patients with solid tumors. The results of our meta-analysis may provide high-level evidences to verify the prognostic effect of Axl in solid cancers.

\section{Methods}

\section{Search strategy and eligible studies}

We performed a comprehensive search of the electronic databases including PubMed, Embase, the Cochrane Library and Web of Science, using the keywords "solid tumor OR cancer OR carcinoma OR neoplasm” AND “Axl OR Gas6
OR ARK OR Tyro7 OR UFO OR AXL receptor tyrosine kinase" AND "prognosis". Both titles and abstracts were carefully screened by 2 independent reviewers to exclude irrelevant studies. Duplicate studies were removed, and additional studies were identified by a manual search of references cited in the original studies. If different studies on same patient population were identified, only the one with the largest patient number was included based on the updated PRISMA criteria. ${ }^{7}$ A flow chart of the search process is presented in Figure 1.

\section{Inclusion and exclusion criteria}

To be eligible for inclusion in this meta-analysis, a study was required to meet the following inclusion criteria: (1) published in English and full text is accessible; (2) provided survival information such as relapse-free survival (RFS) and OS associated with Axl or Gas6 expression; (3) participants

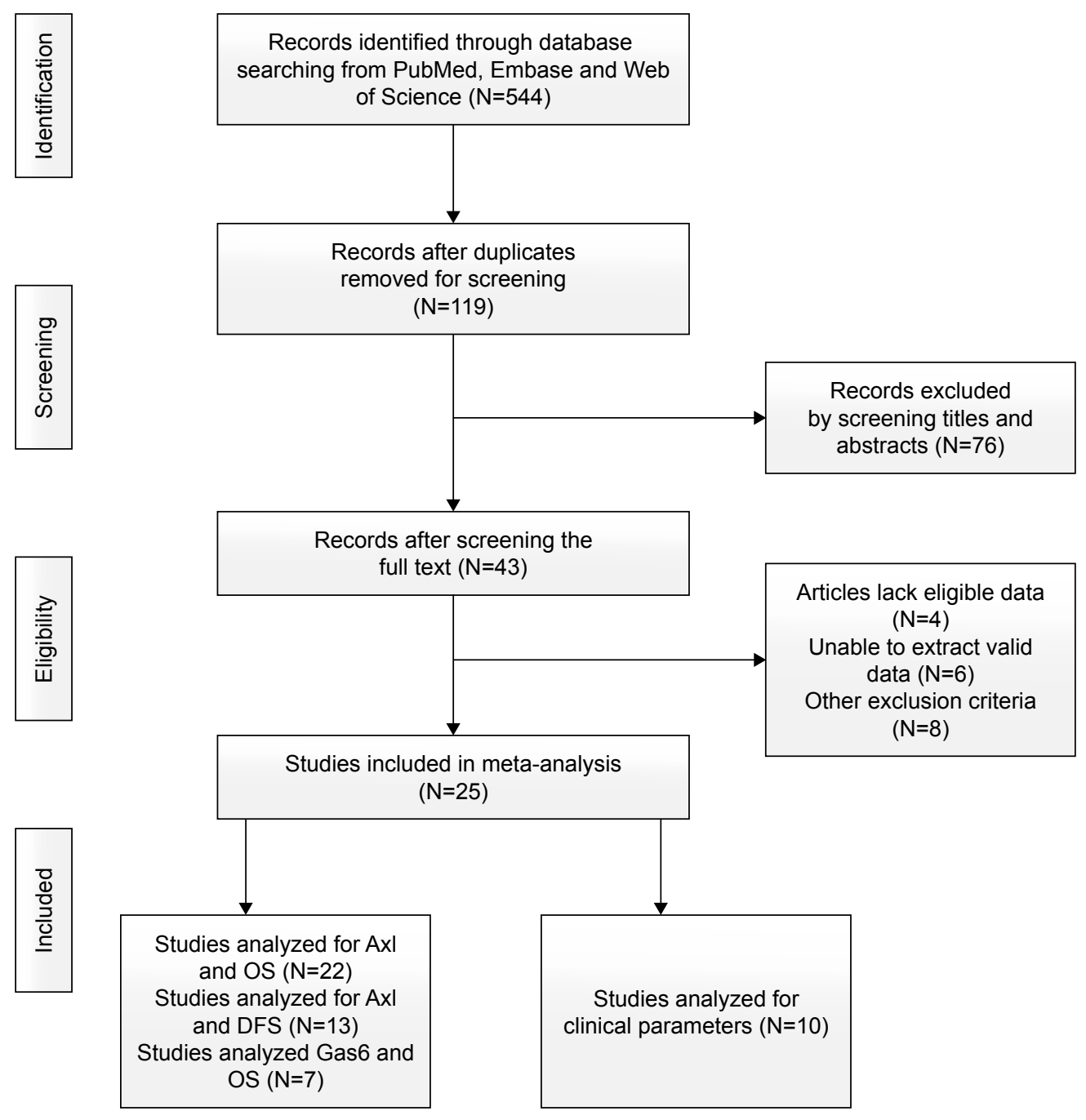

Figure I Flow chart of the selection process.

Abbreviations: DFS, disease-free survival; OS, overall survival. 
must have had a solid tumor; (4) the study should provided hazard ratio (HR) and $95 \%$ confidence interval (CI), or data that could be used to estimate the HRs and $95 \%$ CIs, or Kaplan-Meier survival curves with sufficient data to extract HRs and 95\% CIs; and (5) the study must be a peer-reviewed and published original article. Exclusion criteria: (1) review articles, case reports, letters, comments or book chapters, and studies that had (2) no data on survival or RFS or (3) insufficient data for calculation of HRs.

\section{Data extraction and quality assessment}

According to the inclusion and exclusion criteria, 2 reviewers (SZ and YXT) searched and assessed the studies independently. Studies were chosen by consensus. The following items were extracted from each study: author, publication year, country, patient number, follow-up period, patient clinicopathological features, Axl/Gas6 detection method, cut-off criteria, statistical method and HR of OS and/or DFS. If HR was not available, we applied GetData Graph Digitizer 2.3 to digitize and extract survival information from the Kaplan-Meier curves. Manual calculation methods were also applied to estimate the HR and 95\% CI according to the literature. ${ }^{8}$

Quality assessment of the included studies was performed by 2 independent reviewers (XSX and JXY) according to REMARK (REporting recommendations for tumor MARKer prognostic studies) guideline. ${ }^{9}$ As previously published, ${ }^{10}$ we used the 20 -item scale for quality assessment (Table 1). In brief, this scale includes information on study design, assay method, outcomes and statistical analysis method. Each item is scored as follows: 2 points if it is clearly indicated, 1 point if the description is partial or unclear and 0 point if it is not mentioned in the study. Higher scores represent better quality of the original study.

\section{Statistical analysis}

Cochrane RevMan 5.3.0 (The Cochrane Collaboration, London, UK) was applied for meta-analysis. Individual HRs and 95\% CIs were combined from individual studies to determine the overall effective value of Axl and Gas6. For the overall result, an observed HR $>1$ implied that Axl/Gas6 overexpression was a risk factor for OS. The $\chi^{2}$ test was used to evaluate heterogeneity between studies. A $p$-value $<0.05$ indicated that the heterogeneity between individual studies was statistically significant. The total variation among studies was estimated by $I^{2}$. An $I^{2}$ value $<25 \%$ suggested low heterogeneity, and fixed-effects model was used. If heterogeneity was significant, a combined HR was
Table I Items for quality assessment

\begin{tabular}{|c|c|}
\hline Item & Item description \\
\hline \multicolumn{2}{|l|}{ Introduction } \\
\hline Item I & $\begin{array}{l}\text { Give rationale for study hypothesis and } \\
\text { objectives }\end{array}$ \\
\hline \multicolumn{2}{|c|}{ Materials and methods } \\
\hline \multicolumn{2}{|l|}{ Patients } \\
\hline Item 2 & $\begin{array}{l}\text { Describe patient characteristics: list all } \\
\text { candidate variables (eg, age, menopause } \\
\text { status, disease type, etc) }\end{array}$ \\
\hline Item 3 & Describe treatment received by the patients \\
\hline \multicolumn{2}{|r|}{ 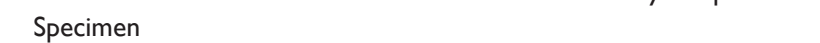 } \\
\hline Item 4 & $\begin{array}{l}\text { Describe type of the specimen and } \\
\text { control samples }\end{array}$ \\
\hline \multicolumn{2}{|c|}{ Assay methods } \\
\hline Item 5 & $\begin{array}{l}\text { Describe in details the methods used to } \\
\text { detect AxI/Gas6 (eg, quantitative PCR or } \\
\text { immunohistochemical staining, etc) }\end{array}$ \\
\hline Item 6 & Manufacturer and catalog number for reagents \\
\hline Item 7 & $\begin{array}{l}\text { Evaluation methods: cut-off point } \\
\text { determination }\end{array}$ \\
\hline Item 8 & $\begin{array}{l}\text { Negative and positive control and blind } \\
\text { methods applied }\end{array}$ \\
\hline \multicolumn{2}{|c|}{ Study design } \\
\hline Item 9 & Give rationale for sample size \\
\hline Item 10 & $\begin{array}{l}\text { Case selection criteria: state inclusion and/or } \\
\text { exclusion criteria; whether prospective or } \\
\text { retrospective; whether stratification or } \\
\text { matching was employed; the period from } \\
\text { which cases were taken }\end{array}$ \\
\hline Item II & $\begin{array}{l}\text { Follow-up description: follow-up period or } \\
\text { median follow-up time }\end{array}$ \\
\hline Item 12 & $\begin{array}{l}\text { Outcome description: define all clinical end } \\
\text { points examined }\end{array}$ \\
\hline \multicolumn{2}{|c|}{ Statistical analysis } \\
\hline Item 13 & $\begin{array}{l}\text { Specify all statistical methods and information } \\
\text { (methods to analyze correlation of Axl/Gas } 6 \\
\text { expression and clinical parameters, methods } \\
\text { to analyze overall survival and/or disease-free } \\
\text { survival, } p \text {-value, statistical software applied) }\end{array}$ \\
\hline \multicolumn{2}{|r|}{ a } \\
\hline \multicolumn{2}{|c|}{ Data and analysis } \\
\hline Item I4 & $\begin{array}{l}\text { Describe Axl/Gas } 6 \text { expression in all solid } \\
\text { cancer patients and its correlation to } \\
\text { standard prognostic variables }\end{array}$ \\
\hline Item 15 & $\begin{array}{l}\text { Present univariate analyses showing the } \\
\text { relation between Axl/Gas6 and outcome, } \\
\text { with estimated effect (eg, hazard ratio) }\end{array}$ \\
\hline Item 16 & $\begin{array}{l}\text { For multivariate analyses, report estimated } \\
\text { effects (eg, hazard ratio) with confidence } \\
\text { interval for Axl/Gas6, adjusted for } \\
\text { other risk factors }\end{array}$ \\
\hline Item 17 & $\begin{array}{l}\text { Missing data: describe the missing number } \\
\text { value for Axl/Gas6 and how to deal with it }\end{array}$ \\
\hline \multicolumn{2}{|l|}{ Discussion } \\
\hline Item 18 & $\begin{array}{l}\text { Interpret the results in the context of } \\
\text { hypotheses and other relevant studies }\end{array}$ \\
\hline Item 19 & $\begin{array}{l}\text { Discussion of potential confounding } \\
\text { factor of the study }\end{array}$ \\
\hline Item 20 & $\begin{array}{l}\text { Discussion of limitation of the study, clinical } \\
\text { value of Axl/Gas } 6 \text { and implication for future } \\
\text { investigation }\end{array}$ \\
\hline
\end{tabular}


calculated by random-effects model. Publication bias was assessed by Begg's funnel plot and by Egger's linear regression method ${ }^{11,12}$ performed by Stata SE 12.0 (Stata Corp LP, College Station, TX, USA). A $p$-value $>0.05$ suggested that there was no significant publication bias. If $p$-value was $<0.05$, "trim-and-fill" method was used to test the potential influence of unpublished studies on the summary result.

\section{Results}

\section{Search results and characteristics of the} eligible studies

In total, 544 studies were identified by our search, of which 110 articles were from PubMed and 434 were from other databases (Figure 1). After removing duplicate studies and screening of titles and abstracts, 43 articles were found to be potentially eligible for our meta-analysis. Eventually, 25 studies fulfilled our inclusion criteria. ${ }^{13-37}$ Among the included articles, 22 studies ${ }^{14-22,24-26,28-37}$ had available data to analyze the association between Axl expression and OS, 13 studies $^{14,18,21,22,27-29,31,33-37}$ had available data to analyze the association between Axl expression and DFS and 7 studies $^{13-15,22-24,32}$ contained data on Gas6 expression and its relation with $\mathrm{OS}$.

Together, the 25 eligible studies involved 3,344 patients with solid tumor. The sample size of included cohorts ranged from 35 to 509, with a median of 88 patients. In terms of cancer type, 4 studies evaluated breast cancer, followed by hepatocellular carcinoma $(n=2)$, esophageal cancer $(n=2)$, lung cancer $(n=2)$ and other cancer types (glioblastoma multiforme, renal cell carcinoma, pancreatic cancer, oral squamous cell carcinoma (OSCC), ovarian adenocarcinoma, osteosarcoma, nasopharyngeal carcinoma, colorectal cancer, etc). Other information of included studies is summarized in Table 2.

\section{Correlation of Axl expression and OS in all solid tumor patients}

As shown in Figure 2, on pooling data of correlation between OS and Axl expression from 22 studies (3,170 patients), the combined HR was calculated to be 2.03 (95\% CI 1.73-2.37, $p<0.00001)$. This indicated that Axl overexpression was associated with a 2.03-fold increase in mortality in all solid tumor patients. No significant heterogeneity across studies was found $\left(I^{2}=18 \%, p=0.23\right)$.

In subgroup analysis of different cancer types, Axl overexpression was correlated with shorter OS in hepatocellular carcinoma, esophageal cancer and lung cancer, with a combined HR of 1.89 (95\% CI 1.37-2.60, $p<0.0001$ ), 1.99
(95\% CI 1.28-3.11, $p=0.002)$ and 1.67 (95\% CI 1.04-2.67, $p<0.03)$, respectively. For breast cancer, there was no significant correlation between Axl expression and OS, with a combined HR of 1.63 (95\% CI $0.69-3.83, p=0.27)$ (Figure 3A-D).

\section{Impact of Axl expression on DFS in all solid tumor patients}

We analyzed the impact of Axl expression on DFS in all solid tumor patients with available data. From 13 studies, the combined HR for impact of Axl overexpression on DFS was 1.85 (1,585 patients, 95\% CI 1.44-2.38, $p<0.00001)$, which indicated that the overexpression of Axl increases the risk of disease recurrence by 1.85-fold (Figure 4). No significant heterogeneity was detected among studies $\left(I^{2}=37 \%, p=0.09\right)$.

\section{Impact of Gas6 expression on OS in all solid tumor patients}

The correlation of OS and Gas6 expression was analyzed in 7 studies with a total of 807 patients. As illustrated in Figure 5, the combined HR was 1.22 (95\% CI 0.77-1.93, $p=0.39$ ), which suggested that the accumulated data did not show significant correlation between Gas6 expression and OS. In addition, significant heterogeneity across studies was found $\left(I^{2}=58 \%, p=0.03\right)$.

\section{Correlation between Axl expression and clinicopathological characteristics}

We found that Axl overexpression was correlated with poor prognosis in all solid tumors. To further analyze the correlation between Axl and clinicopathological characteristics, we performed a meta-analysis with the available data. In all the included studies, Axl expression was significantly associated with poor (poor vs well or moderate) differentiation grade $(1,227$ patients; pooled odds ratio [OR]: $1.95,95 \%$ CI 1.29-2.97, $p=0.002$ ), advanced (stage III/IV) TNM stage (804 patients; pooled OR: 2.81, 95\% CI 1.65-4.80, $p=0.002$ ), lymph node metastasis (613 patients; pooled OR: $2.99,95 \%$ CI $1.54-5.79, p=0.001)$ and distant metastasis (374 patients; pooled OR: 4.14, 95\% CI 2.20-7.79, $p<0.0001$ ) (Figure 6A-D).

\section{Assessment of publication bias}

We evaluated the publication bias of the correlation between Axl expression and OS and DFS. As shown in Figure 7A and B, the funnel plots were symmetrical. In addition, Egger's test showed no significant publication bias in meta-analysis of 


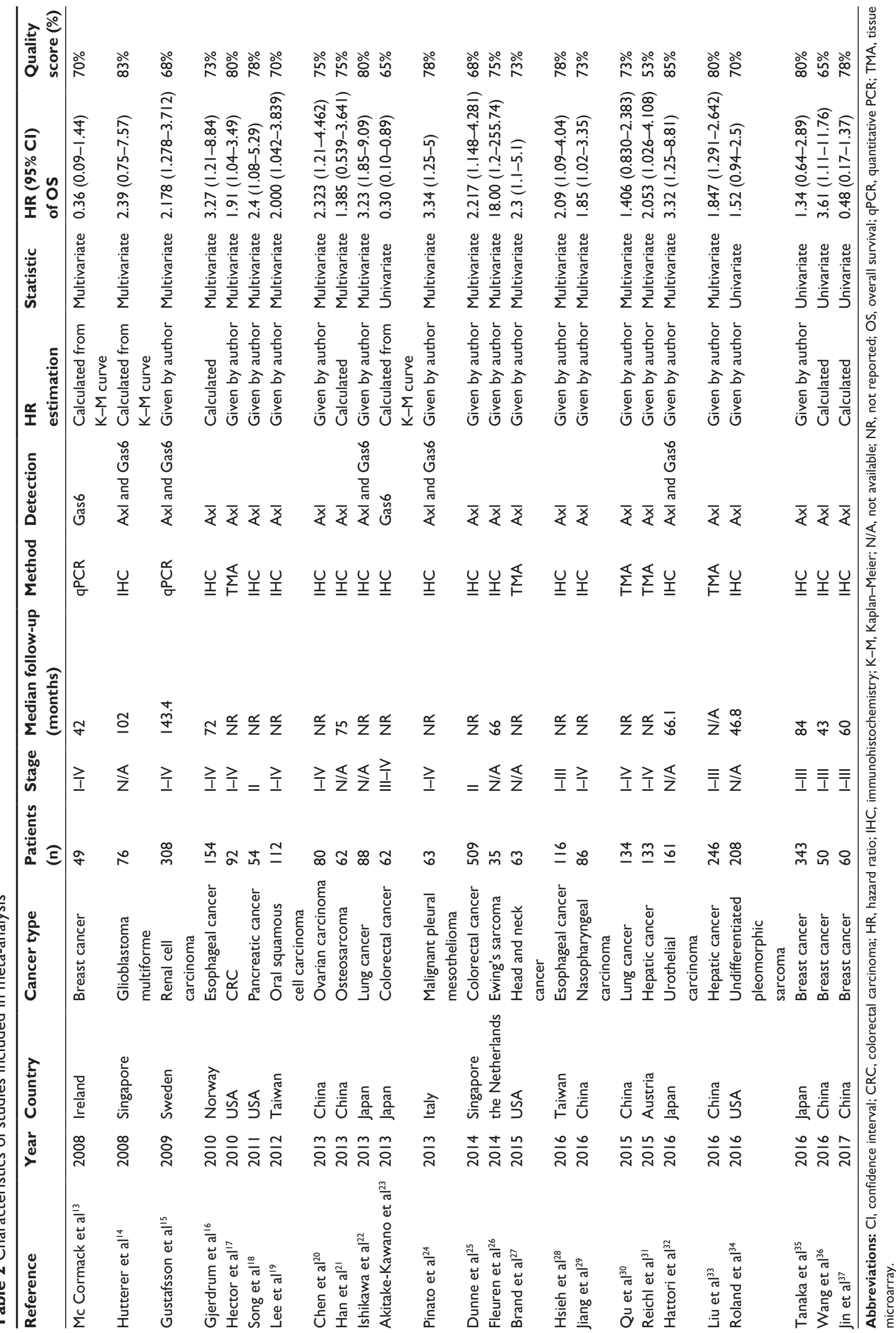




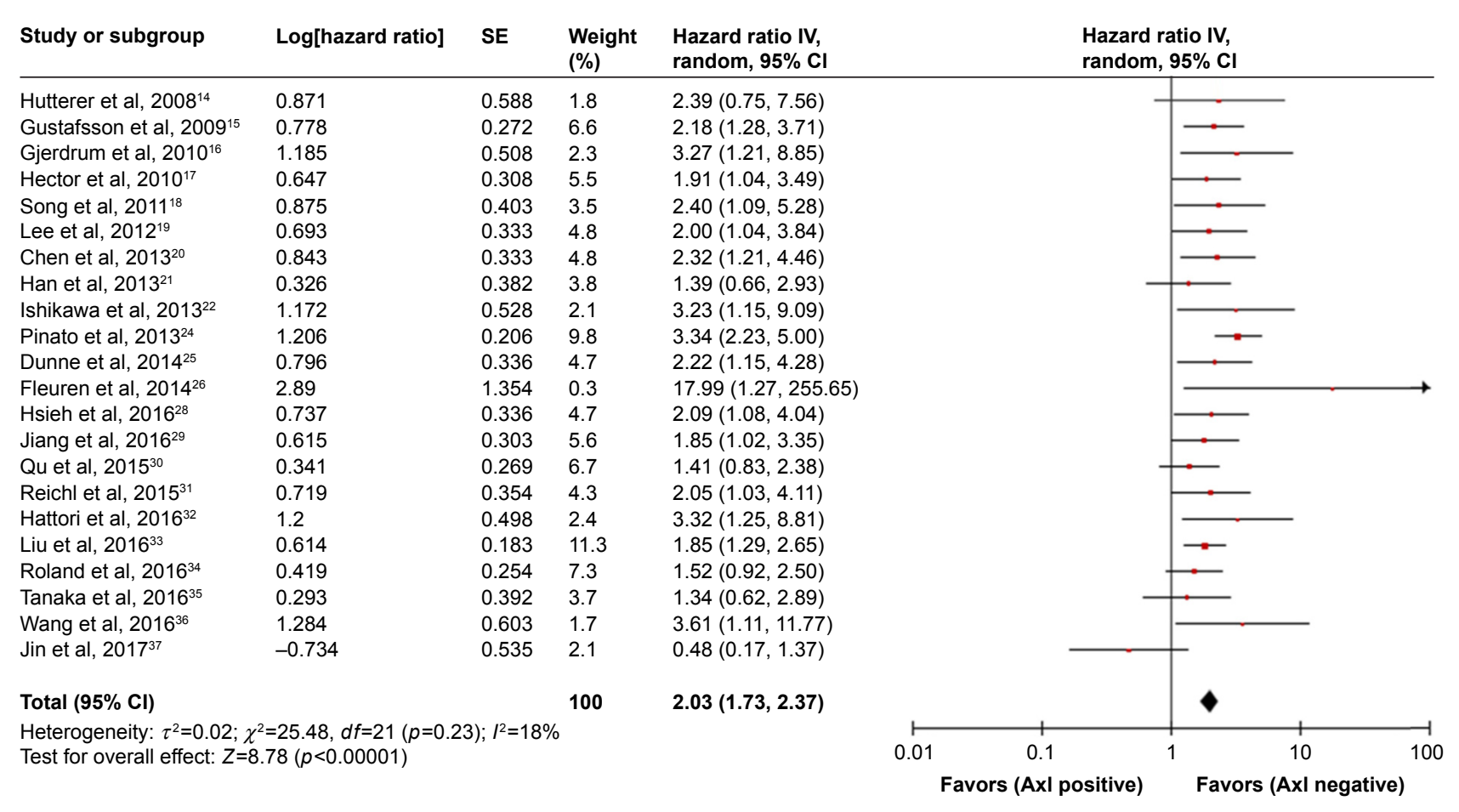

Figure 2 Forest plot of the hazard ratio for overall survival associated with Axl expression in all solid tumor patients. Abbreviations: $\mathrm{Cl}$, confidence interval; IV, inverse variance; SE, standard error.

OS and DFS ( $p=0.55$ and $p=0.19$, respectively). In addition, there was no significant publication bias in meta-analysis of Gas6 expression and OS (Figure 8), with a symmetrical funnel plot. Begg's regression $(p=1)$ and Egger's linear regression ( $p=0.556$ ) also confirmed the result.

\section{Discussion}

It has been widely studied and proved that the activation of Gas6/Axl pathway is implicated in the development and progression of cancer. The activation of Axl is dependent on its overexpression as it has been found overexpressed in various malignancies ${ }^{5}$ and related to poor prognosis. To the best of our knowledge, this meta-analysis is the first and most comprehensive study to systematically explore the impact of Axl and Gas6 expression on prognosis in various solid malignancies.

In the present study, we included 25 studies with 3,344 patients and analyzed whether Axl is a significant prognostic risk factor in solid tumors. In general, Axl was overexpressed in cancerous tissue compared to normal control tissue (average: 54.7\% vs 12.7\%) (Table S1). First, we analyzed the overall impact of Axl expression on OS from 22 studies. Our results demonstrated that Axl overexpression significantly correlated with a 2.03 -fold $(95 \%$ CI 1.73-2.37) increase in mortality in all solid tumor patients.
In terms of DFS, the meta-analysis of 13 studies indicated that overexpression of Axl was significantly correlated with a shorter DFS time, with a pooled HR of 1.85 (95\% CI 1.44-2.38). No significant heterogeneity and publication bias were detected among studies, which suggested that our results of Axl overexpression indicating poor OS and DFS are convincing. As Axl expression was relatively high in cancerous tissue (54.7\%) compared to normal counterpart $(12.7 \%)$, Axl can be used as a sensitive and potent indicator for predicting outcome of solid malignancies.

Furthermore, we stratified the results by different cancer types. Our subgroup analysis showed that Axl overexpression was correlated with decreased OS in hepatocellular carcinoma (OR: 1.89, 95\% CI 1.37-2.60), esophageal cancer (OR: 1.99, 95\% CI 1.28-3.11) and lung cancer (OR: 1.67, 95\% CI 1.04-2.67). The subgroup results are in concordance with previous in vitro data. In hepatocellular cancer cell lines, Gas6/Axl can enhance cell invasiveness through transcriptional activation of Slug which induces epithelialmesenchymal transition (EMT). ${ }^{38}$ Studies also found that Axl overexpression correlated with enhanced cell motility and invasiveness in lung cancer. ${ }^{39}$ In addition, activation of Axl could cause resistance of EGFR-targeted therapy in lung cancer. ${ }^{40}$ In esophageal cancer, it has been shown that genetic silencing of Axl can inhibit proliferation, migration 


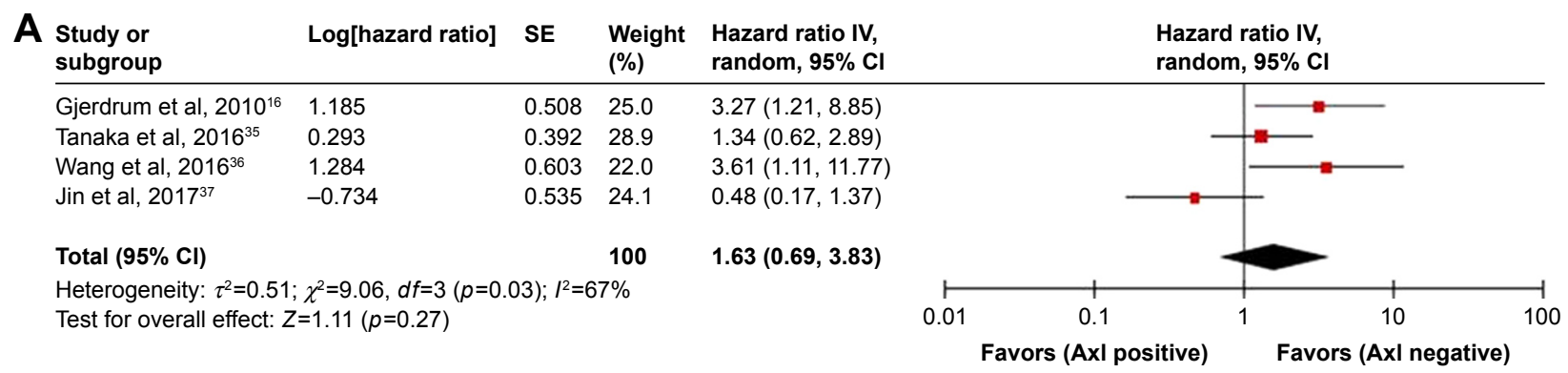

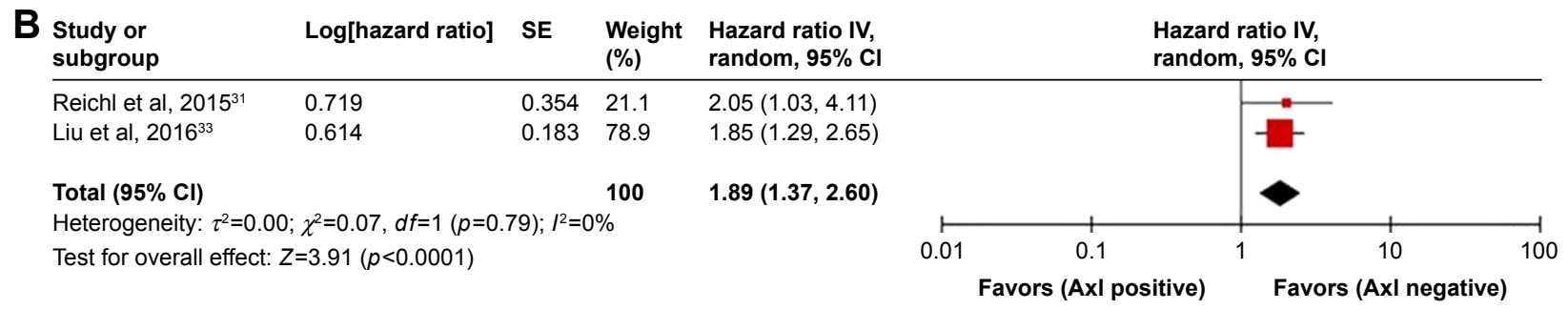

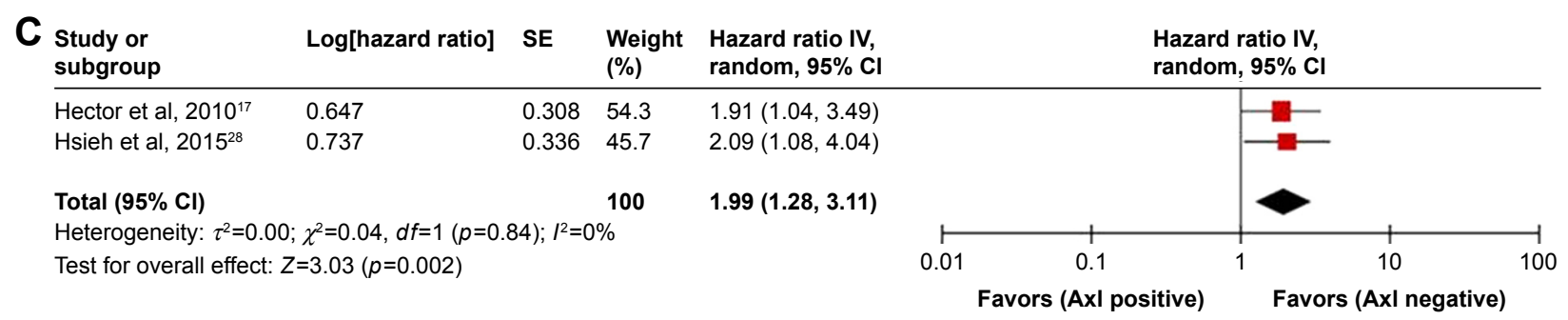

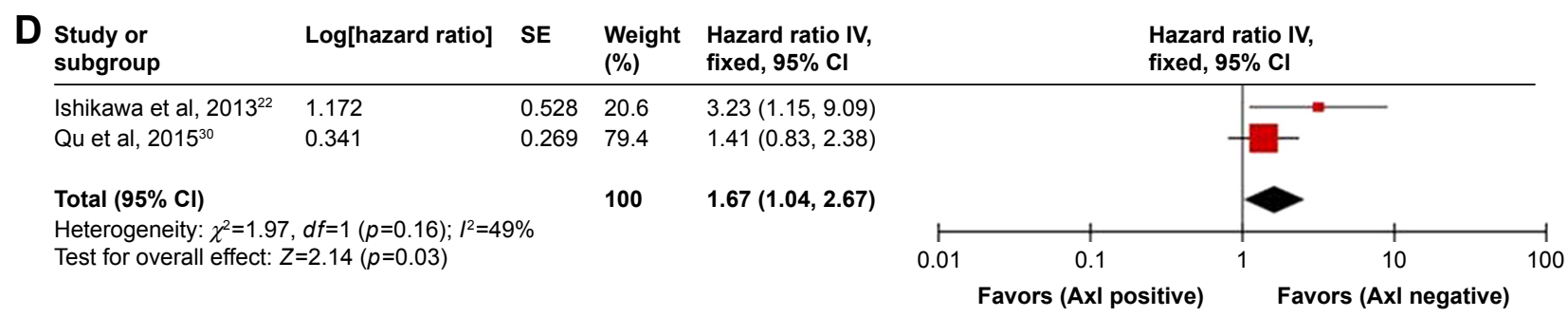

Figure 3 Forest plots of the hazard ratio for overall survival associated with Axl expression in breast cancer (A), liver cancer (B), esophageal cancer (C) and lung cancer (D). Abbreviations: $\mathrm{Cl}$, confidence interval; IV, inverse variance; SE, standard error.

and invasion. ${ }^{41}$ Although many studies provided substantial evidences of Axl's biological significance in breast cancer development, ${ }^{42-44}$ our meta-analysis failed to show significant correlation between Axl expression and OS in breast cancer patients. More translational studies are needed to further explore the role of Axl signaling pathway in breast cancer.

Clinical parameters such as differentiation grade, lymph node involvement, distant metastasis and TNM stages are critical factors to predict outcomes in solid tumors. Studies have demonstrated that Gas6/Axl pathway activation could initiate EMT process and enhance cancer cell invasiveness. ${ }^{45} \mathrm{In}$ our meta-analysis, we evaluated the relationship between Axl expression and various clinicopathological characteristics.
Our results indicated that poor differentiation (OR: 1.95, 95\% CI 1.29-2.97), advanced TNM stage (OR: 2.81, 95\% CI 1.65-4.80), positive lymph node metastasis (OR: 2.99, 95\% CI 1.54-5.79) and positive distant metastasis (OR: 4.14, 95\% CI 2.20-7.79) are correlated with Axl overexpression. These findings suggest that Axl could serve as a valuable predicting factor in solid tumors.

As the major ligand of Axl, Gas6 may activate Axl signaling pathway and initiate its downstream events. Researchers have found that Gas6 is overexpressed in certain cancers compared to normal adjacent tissues ${ }^{46}$ and can enhance cancer cell viability and motility in vitro. ${ }^{47}$ Jiang et al also proved that in OSCC patients, serum Gas6 level is elevated 


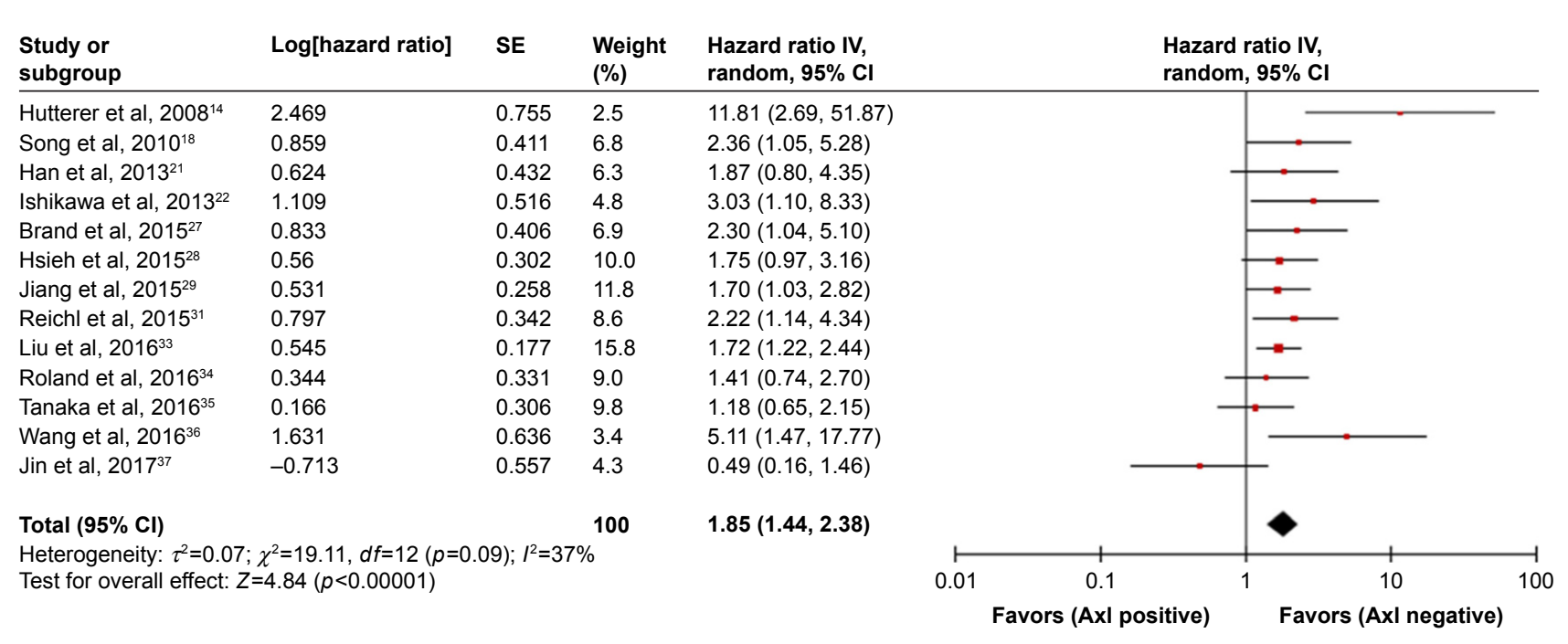

Figure 4 Forest plot of the hazard ratio for disease-free survival associated with Axl expression in all solid tumor patients. Abbreviations: $\mathrm{Cl}$, confidence interval; IV, inverse variance; SE, standard error.

and it can be an independent factor to predict prognosis (HR from multivariate analysis: $2.07, p<0.05) .{ }^{48}$ Due to limited number of included studies, our meta-analysis of relationship between Gas6 expression and OS showed no statistical significance. However, we noted that there is significant heterogeneity between studies $\left(I^{2}=58 \%\right)$. We therefore conducted the sensitivity examination by deleting single study from the meta-analysis and found that if the study by Akitake-Kawano et $\mathrm{a}^{23}$ was removed, the pooled HR for the effect of Gas 6 overexpression on OS would be 1.44 (95\% CI $1.02-2.04, p=0.04)$ and the heterogeneity was eliminated $\left(I^{2}=27 \%\right)$ (Figure S1). This discrepancy might be due to the following possibility: (1) insufficient studies were included; (2) heterogeneity between different types of solid tumors was poor; and (3) Gas6 has a complex pathophysiological role. Unlike Axl, Gas6 is a secreted protein that is usually released into circulation. In terms of cancer development, it is still not clear whether tumor tissues secrete Gas6 to facilitate cancer cell proliferation or other stromal cells secrete Gas6 to support tumor growth. To answer this question, more studies are needed to elucidate the underlining mechanism.

According to our comprehensive quality assessment system, all included studies had moderate- to high-quality scores (Table S2). Apart from the animating results, there are several limitations of this meta-analysis. First, although it included various types of cancers, there is limited number of studies for each specific cancer type. It is inconclusive whether Axl expression correlates with OS in a specific type of cancer. Second, impact of Gas6 expression on OS is still inconclusive. Gas6 and Axl expression might be detected together in future study to explore whether it is more accurate in predicting outcome. Third, different staining protocols, reagents and cut-off evaluation were applied in individual studies. This heterogeneity was difficult to eliminate which may generate bias in the overall result. Finally, although random-effect model was applied, heterogeneity between studies still existed

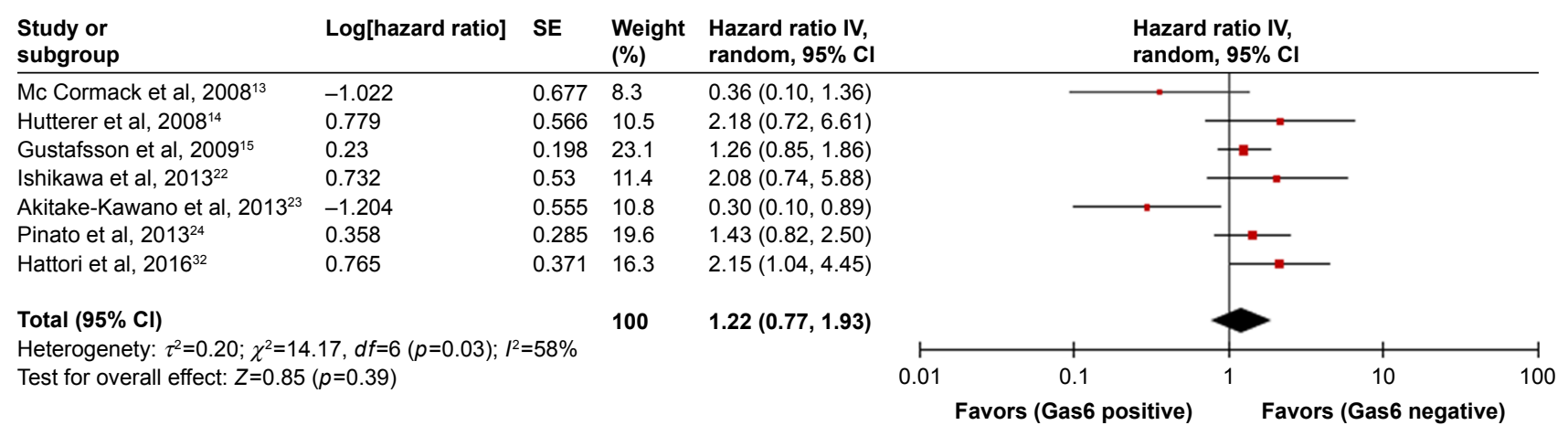

Figure 5 Forest plot of the hazard ratio for overall survival associated with Gas6 expression in all solid tumor patients. Abbreviations: $\mathrm{Cl}$, confidence interval; IV, inverse variance; SE, standard error. 


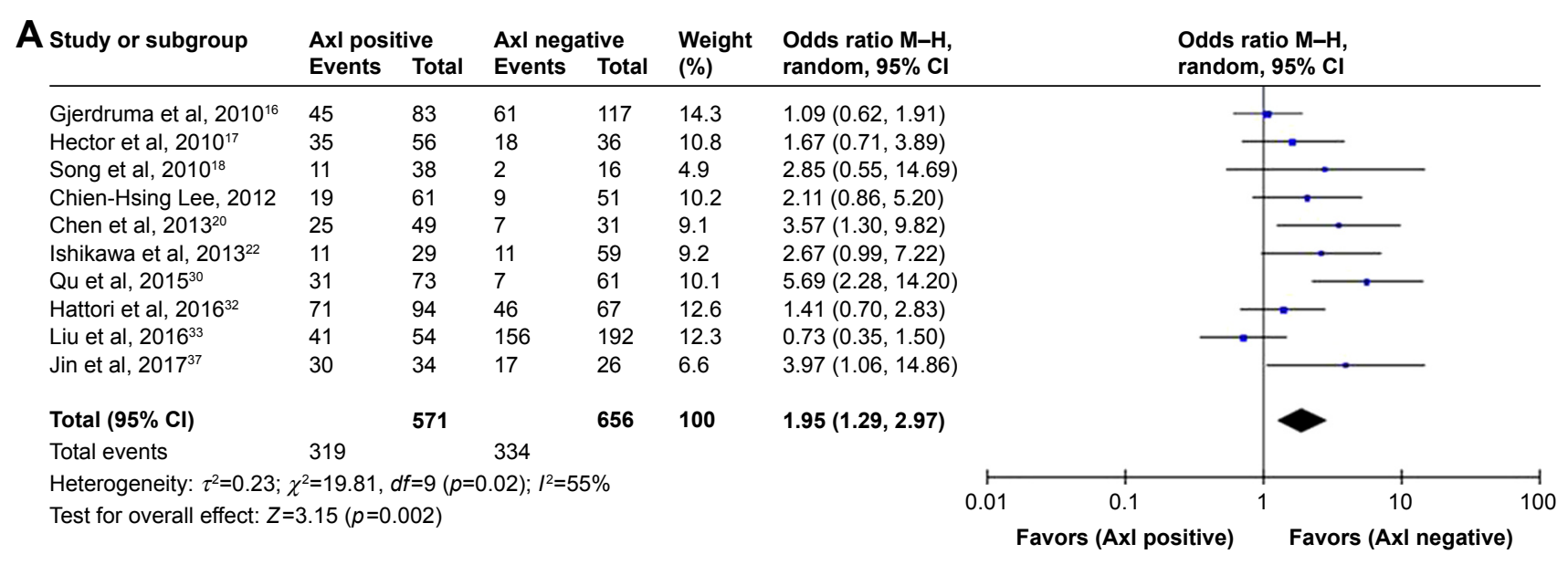

\begin{tabular}{|c|c|c|c|c|c|c|c|c|c|}
\hline \multirow{2}{*}{$\begin{array}{l}\text { B Study or subgroup } \\
\qquad \text { Hector et al, } 2010^{17}\end{array}$} & \multicolumn{2}{|c|}{ Axl positive } & \multicolumn{2}{|c|}{ Axl negative } & $\begin{array}{l}\text { Weight } \\
(\%)\end{array}$ & $\begin{array}{l}\text { Odds ratio } \mathrm{M}-\mathrm{H} \text {, } \\
\text { random, } 95 \% \mathrm{Cl}\end{array}$ & \multicolumn{2}{|c|}{$\begin{array}{l}\text { Odds ratio } \mathrm{M}-\mathrm{H} \text {, } \\
\text { random, } 95 \% \mathrm{Cl}\end{array}$} & \\
\hline & 29 & 53 & 12 & 33 & 14.7 & $2.11(0.87,5.16)$ & & & \\
\hline Chien-Hsing Lee, 2012 & 40 & 61 & 22 & 51 & 16.5 & $2.51(1.17,5.40)$ & & & \\
\hline Chen et al, $2013^{20}$ & 37 & 49 & 14 & 31 & 13.8 & $3.74(1.43,9.79)$ & & & \\
\hline Jiang et al, $2015^{29}$ & 49 & 59 & 11 & 27 & 13.0 & $7.13(2.56,19.88)$ & & & \\
\hline Qu et al, $2015^{30}$ & 67 & 73 & 44 & 61 & 13.2 & $4.31(1.58,11.79)$ & & & \\
\hline Liu et al, $2016^{33}$ & 29 & 54 & 46 & 192 & 18.5 & $3.68(1.96,6.91)$ & & $\longrightarrow$ & \\
\hline Jin et al, $2017^{37}$ & 5 & 34 & 8 & 26 & 10.4 & $0.39(0.11,1.37)$ & & & \\
\hline Total $(95 \% \mathrm{Cl})$ & & 383 & & 421 & 100 & $2.81(1.65,4.80)$ & & & \\
\hline Total events & 256 & & 157 & & & & & & \\
\hline \multicolumn{5}{|c|}{ Heterogeneity: $\tau^{2}=0.30 ; \chi^{2}=14.75, d f=6(p=0.02) ; l^{2}=59 \%$} & & 0.01 & 0.1 & 10 & 100 \\
\hline \multicolumn{5}{|c|}{ Test for overall effect: $Z=3.78(p=0.0002)$} & & 0.01 & $(A x)_{1}$ & Favors (Ax) & \\
\hline
\end{tabular}

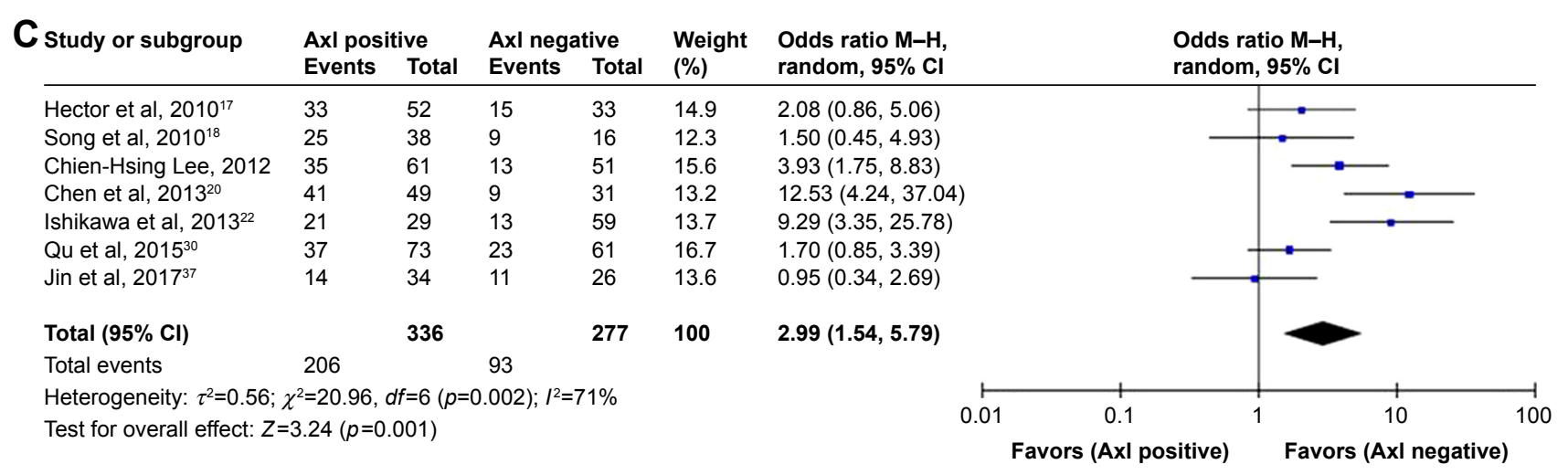

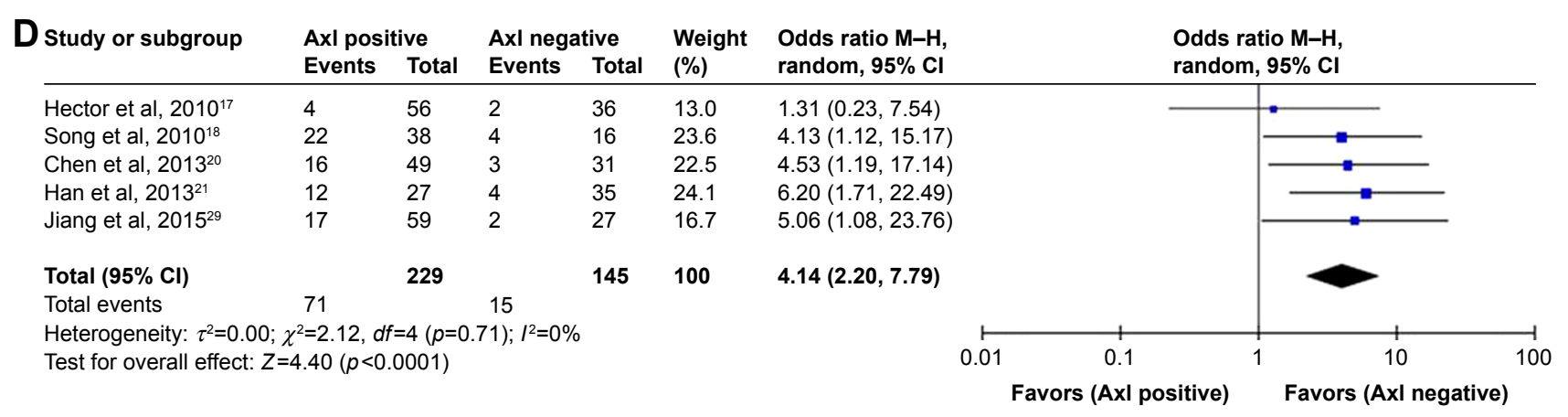

Figure 6 Relationship between Axl expression and poor differentiation grade (A), late (III/IV stage) TNM stage (B), lymph node metastasis (C) and distant metastasis (D) in all solid tumor patients.

Abbreviations: $\mathrm{Cl}$, confidence interval; LN, lymph node; $\mathrm{M}-\mathrm{H}$, Mantel-Haenszel. 

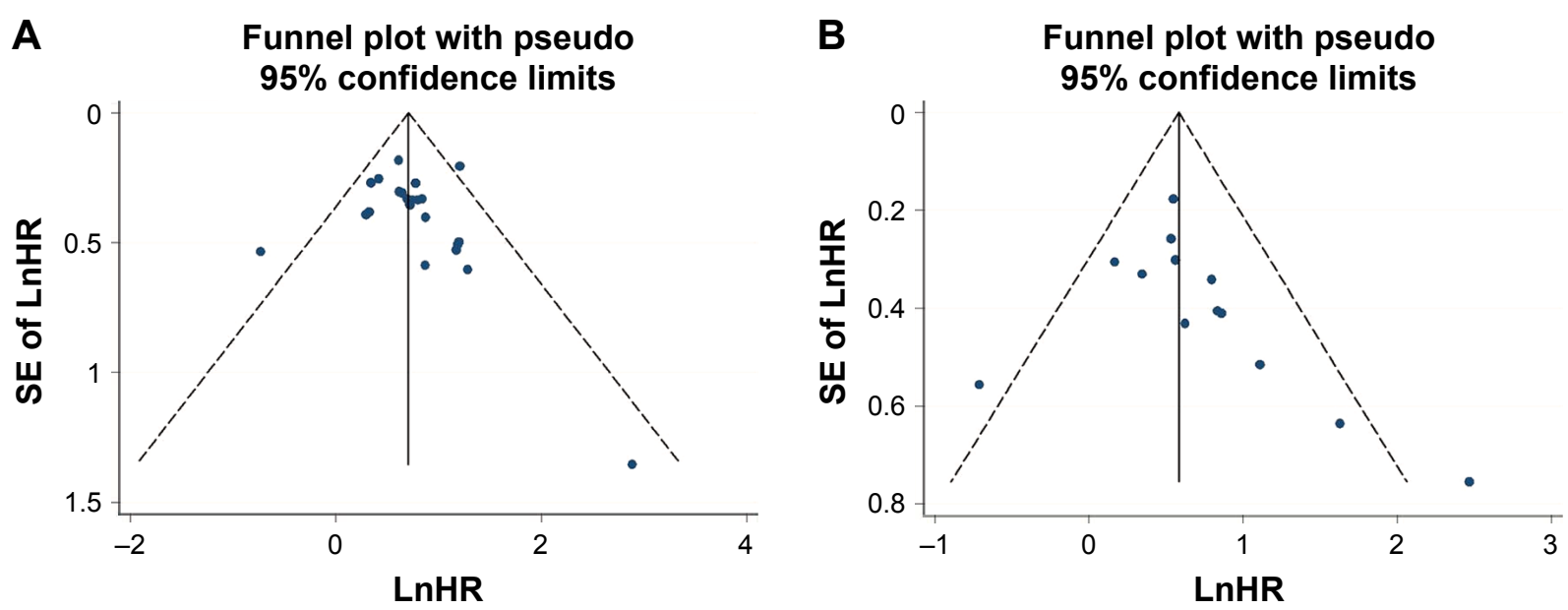

Figure 7 Funnel plots of HR of Axl expression for OS (A) and DFS (B) in all solid tumor patients.

Abbreviations: DFS, disease-free survival; HR, hazard ratio; Ln, natural logarithm; OS, overall survival; SE, standard error.

and this may affect the overall result. Thus, more high-quality studies are needed to draw more reliable conclusions.

In spite of the limitations mentioned above, this comprehensive meta-analysis has many valuable implications. First, the present study evaluated for the first time the prognostic value of Axl expression in all solid tumor patients. We demonstrated and validated that Axl is a prognostic factor for unfavorable outcome in solid tumor. Second, we also proved that Axl overexpression is correlated with clinical parameters such as advanced stage, poor differentiation grade, lymph node metastasis and distant metastasis. In conclusion, according to our meta-analysis, Axl is a promising biomarker for predicting prognosis in solid tumor. Our results may provide evidence for further research on biological role of Gas6/Axl axis in a specific type of cancer.

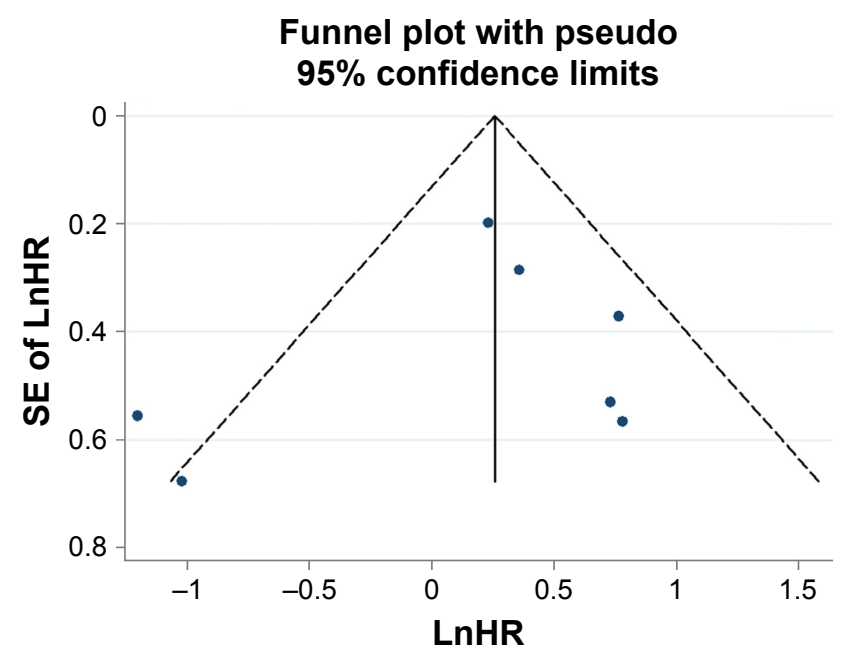

Figure 8 Funnel plot of HR of Gas6 expression for OS in all solid tumor patients. Abbreviations: HR, hazard ratio; OS, overall survival; SE, standard error.

\section{Acknowledgment}

This research was supported by a grant from the National Natural Science Foundation of China (number 81201820).

\section{Disclosure}

The authors report no conflicts of interest in this work.

\section{References}

1. Siegel RL, Miller KD, Jemal A. Cancer statistics. CA Cancer J Clin. 2017;67(1):7-30.

2. Janssen JW, Schulz AS, Steenvoorden AC, et al. A novel putative tyrosine kinase receptor with oncogenic potential. Oncogene. 1991;6(11): 2113-2120.

3. O’Bryan JP, Frye RA, Cogswell PC, et al. Axl, a transforming gene isolated from primary human myeloid leukemia cells, encodes a novel receptor tyrosine kinase. Mol Cell Biol. 1991;11(10):5016-5031.

4. Lemke G, Rothlin CV. Immunobiology of the TAM receptors. Nat Rev Immunol. 2008;8(5):327-336.

5. Brown M, Black JR, Sharma R, Stebbing J, Pinato DJ. Gene of the month: Axl. J Clin Pathol. 2016;69(5):391-397.

6. Feneyrolles C, Spenlinhauer A, Guiet L, et al. Axl kinase as a key target for oncology: focus on small molecule inhibitors. Mol Cancer Ther. 2014; 13(9):2141-2148.

7. Moher D, Liberati A, Tetzlaff J, Altman DG; PRISMA Group. Preferred reporting items for systematic reviews and meta-analyses: the PRISMA statement. PLoS Med. 2009;6(7):e1000097.

8. TierneyJF, Stewart LA, Ghersi D, Burdett S, Sydes MR. Practical methods for incorporating summary time-to-event data into meta-analysis. Trials. 2007;8:16.

9. McShane LM, Altman DG, Sauerbrei W, Taube SE, Gion M, Clark GM; Statistics Subcommittee of the NCI-EORTC Working Group on Cancer Diagnostics. REporting recommendations for tumour MARKer prognostic studies (REMARK). Eur J Cancer. 2005;41(12):1690-1696.

10. Zhang S, Tong YX, Xu XS, Lin H, Chao TF. Prognostic significance of SATB1 in gastrointestinal cancer: a meta-analysis and literature review. Oncotarget. 2017;8(29):48410-48423.

11. Egger M, Davey Smith G, Schneider M, Minder C. Bias in meta-analysis detected by a simple, graphical test. BMJ. 1997;315(7109):629-634.

12. Begg CB, Mazumdar M. Operating characteristics of a rank correlation test for publication bias. Biometrics. 1994;50(4):1088-1101.

13. Mc Cormack O, Chung WY, Fitzpatrick P, et al. Growth arrest-specific gene 6 expression in human breast cancer. Br J Cancer. 2008;98(6): $1141-1146$. 
14. Hutterer M, Knyazev P, Abate A, et al. Axl and growth arrest-specific gene 6 are frequently overexpressed in human gliomas and predict poor prognosis in patients with glioblastoma multiforme. Clin Cancer Res. 2008;14(1):130-138.

15. Gustafsson A, Martuszewska D, Johansson M, et al. Differential expression of Axl and Gas6 in renal cell carcinoma reflecting tumor advancement and survival. Clin Cancer Res. 2009;15(14):4742-4749.

16. Gjerdrum C, Tiron C, Høiby $\mathrm{T}$, et al. Axl is an essential epithelialto-mesenchymal transition-induced regulator of breast cancer metastasis and patient survival. Proc Natl Acad Sci U S A. 2010;107(3):1124-1129.

17. Hector A, Montgomery EA, Karikari C, et al. The Axl receptor tyrosine kinase is an adverse prognostic factor and a therapeutic target in esophageal adenocarcinoma. Cancer Biol Ther. 2010;10(10):1009-1018.

18. Song X, Wang H, Logsdon CD, et al. Overexpression of receptor tyrosine kinase Axl promotes tumor cell invasion and survival in pancreatic ductal adenocarcinoma. Cancer. 2011;117(4):734-743.

19. Lee CH, Yen CY, Liu SY, et al. Axl is a prognostic marker in oral squamous cell carcinoma. Ann Surg Oncol. 2012;19 (Suppl 3):S500-S508.

20. Chen PX, Li QY, Yang Z. Axl and prostasin are biomarkers for prognosis of ovarian adenocarcinoma. Ann Diagn Pathol. 2013;17(5): 425-429.

21. Han J, Tian R, Yong B, et al. Gas6/Axl mediates tumor cell apoptosis, migration and invasion and predicts the clinical outcome of osteosarcoma patients. Biochem Biophys Res Commun. 2013;435(3):493-500.

22. Ishikawa M, Sonobe M, Nakayama E, et al. Higher expression of receptor tyrosine kinase Axl, and differential expression of its ligand, Gas6, predict poor survival in lung adenocarcinoma patients. Ann Surg Oncol. 2013;20 (Suppl 3):S467-S476.

23. Akitake-Kawano R, Seno H, Nakatsuji M, et al. Inhibitory role of Gas6 in intestinal tumorigenesis. Carcinogenesis. 2013;34(7):1567-1574.

24. Pinato DJ, Mauri FA, Lloyd T, et al. The expression of Axl receptor tyrosine kinase influences the tumour phenotype and clinical outcome of patients with malignant pleural mesothelioma. Br J Cancer. 2013 108(3):621-628.

25. Dunne PD, McArt DG, Blayney JK, et al. AXL is a key regulator of inherent and chemotherapy-induced invasion and predicts a poor clinical outcome in early-stage colon cancer. Clin Cancer Res. 2014;20(1): 164-175.

26. Fleuren ED, Hillebrandt-Roeffen MH, Flucke UE, et al. The role of $\mathrm{AXL}$ and the in vitro activity of the receptor tyrosine kinase inhibitor BGB324 in Ewing sarcoma. Oncotarget. 2014;5(24):12753-12768.

27. Brand TM, Iida M, Stein AP, et al. AXL is a logical molecular target in head and neck squamous cell carcinoma. Clin Cancer Res. 2015;21(11): 2601-2612.

28. Hsieh MS, Yang PW, Wong LF, Lee JM. The AXL receptor tyrosine kinase is associated with adverse prognosis and distant metastasis in esophageal squamous cell carcinoma. Oncotarget. 2016;7(24):36956-36970.

29. Jiang C, Zhou L, Wang H, Zhang Q, Xu Y. Axl is a potential cancer prognostic marker for the migration and invasion of nasopharyngeal carcinoma. Adv Clin Exp Med. 2016;25(3):531-537.

30. Qu XH, Liu JL, Zhong XW, Li XI, Zhang QG. Insights into the roles of hnRNP A2/B1 and AXL in non-small cell lung cancer. Oncol Lett. 2015;10(3):1677-1685.

31. Reichl P, Dengler M, van Zijl F, et al. Axl activates autocrine transforming growth factor- $\beta$ signaling in hepatocellular carcinoma. Hepatology. 2015;61(3):930-941.

OncoTargets and Therapy

\section{Publish your work in this journal}

OncoTargets and Therapy is an international, peer-reviewed, open access journal focusing on the pathological basis of all cancers, potential targets for therapy and treatment protocols employed to improve the management of cancer patients. The journal also focuses on the impact of management programs and new therapeutic agents and protocols on
32. Hattori S, Kikuchi E, Kosaka T, et al. Relationship between increased expression of the Axl/Gas6 signal cascade and prognosis of patients with upper tract urothelial carcinoma. Ann Surg Oncol. 2016;23(2): 663-670.

33. Liu J, Wang K, Yan Z, et al. Axl expression stratifies patients with poor prognosis after hepatectomy for hepatocellular carcinoma. PLoS One. 2016;11(5):e0154767.

34. Roland CL, May CD, Watson KL, et al. Analysis of clinical and molecular factors impacting oncologic outcomes in undifferentiated pleomorphic sarcoma. Ann Surg Oncol. 2016;23(7):2220-2228.

35. Tanaka K, Tokunaga E, Inoue $Y$, et al. Impact of expression of vimentin and Axl in breast cancer. Clin Breast Cancer. 2016;16(6):520-526.

36. Wang $\mathrm{C}$, Jin $\mathrm{H}$, Wang $\mathrm{N}$, et al. Gas6/Axl axis contributes to chemoresistance and metastasis in breast cancer through Akt/GSK-3 $\beta / \beta$-catenin signaling. Theranostics. 2016;6(8):1205-1219.

37. Jin G, Wang Z, Wang J, et al. Expression of Axl and its prognostic significance in human breast cancer. Oncol Lett. 2017;13(2):621-628.

38. Lee HJ, Jeng YM, Chen YL, Chung L, Yuan RH. Gas6/Axl pathway promotes tumor invasion through the transcriptional activation of Slug in hepatocellular carcinoma. Carcinogenesis. 2014;35(4):769-775.

39. Wimmel A, Glitz D, Kraus A, Roeder J, Schuermann M. Axl receptor tyrosine kinase expression in human lung cancer cell lines correlates with cellular adhesion. Eur J Cancer. 2001;37(17):2264-2274.

40. Zhang Z, Lee JC, Lin L, et al. Activation of the AXL kinase causes resistance to EGFR-targeted therapy in lung cancer. Nat Genet. 2012;44(8): 852-860.

41. Elkabets M, Pazarentzos E, Juric D, et al. AXL mediates resistance to $\mathrm{PI} 3 \mathrm{Ka}$ inhibition by activating the EGFR/PKC/mTOR axis in head and neck and esophageal squamous cell carcinomas. Cancer Cell. 2015;27(4): 533-546.

42. D’Alfonso TM, Hannah J, Chen Z, Liu Y, Zhou P, Shin SJ. Axl receptor tyrosine kinase expression in breast cancer. J Clin Pathol. 2014; 67(8):690-696.

43. Liu L, Greger J, Shi H, et al. Novel mechanism of lapatinib resistance in HER2-positive breast tumor cells: activation of AXL. Cancer Res. 2009;69(17):6871-6878.

44. Zhang YX, Knyazev PG, Cheburkin YV, et al. AXL is a potential target for therapeutic intervention in breast cancer progression. Cancer Res. 2008;68(6):1905-1915.

45. Vuoriluoto K, Haugen H, Kiviluoto S, et al. Vimentin regulates EMT induction by Slug and oncogenic H-Ras and migration by governing Axl expression in breast cancer. Oncogene. 2011;30(12): 1436-1448.

46. Sun WS, Fujimoto J, Tamaya T. Coexpression of growth arrest-specific gene 6 and receptor tyrosine kinases Axl and Sky in human uterine endometrial cancers. Ann Oncol. 2003;14(6):898-906.

47. Sawabu T, Seno H, Kawashima T, et al. Growth arrest-specific gene 6 and Axl signaling enhances gastric cancer cell survival via Akt pathway. Mol Carcinog. 2007;46(2):155-164.

48. Jiang T, Liu G, Wang L, Liu H. Elevated serum Gas6 is a novel prognostic biomarker in patients with oral squamous cell carcinoma. PLoS One. 2015;10(7):e0133940.

\section{Dovepress}

patient perspectives such as quality of life, adherence and satisfaction. The manuscript management system is completely online and includes a very quick and fair peer-review system, which is all easy to use. Visit http://www.dovepress.com/testimonials.php to read real quotes from published authors. 